\title{
Normalidade, projeção e alteridade em $O$ filho eterno, de Cristovão Tezza e Nascer duas vezes, de Giuseppe Pontiggia
}

\author{
Normality, projection and otherness in O filho eterno, \\ by Cristovão Tezza and \\ Nascer duas vezes, by Giuseppe Pontiggia
}

Carolina Duarte Damasceno

UFU

\begin{abstract}
Resumo
Este artigo se deterá sobre o diálogo entre O filho eterno, de Cristovão Tezza, e Nascer duas vezes, de Giuseppe Pontiggia, que se aproximam por discutirem os impactos da ideia de norma, de desvio de padrão e também por mapearem projeções presentes nas relações. Ao longo da análise, será mostrado como os dois romances desencadeiam, a partir da representação de um relacionamento com um portador de deficiência, uma reflexão sobre os limites e alcances da alteridade.
\end{abstract}

Palavras-chave: normalidade; O filho eterno; Nascer duas vezes; intertextualidade

\section{Abstract}

This article aims to analyzing the intertextuality between Born Twice, by Pontiggia (2002) and Eternal Son, by Cristovão Tezza (2007), portraying how far a barely unspoken dialogue can reach, one that has not yet been properly explored. The proposal is to indicate how the two works approach each other, since both discuss the impact within the idea of norm, deviation, and also how both map the projections presented in interpersonal relationships. The analysis features the way the two books provoke, based on the representation of a relationship with a disabled person, a reflection on the limits and reach of alterity.

Key-words: normality; The Eternal Son; Born Twice, intertextualit 
Em algumas entrevistas dadas após a publicação de $O$ filho eterno ${ }^{1}$, Cristovão Tezza alude a três livros que atuaram nos bastidores da escrita de seu romance: Uma questão pessoal, de Kensaburo $\mathrm{Oe}^{2}$; Nascer duas vezes, de Pontiggia ${ }^{3}$ e Juventude, de Coetzee ${ }^{4}$. Dentre eles, apenas o último - de cunho metalinguístico, mais voltado à trajetória de formação de um escritor -não tem como tema nem a deficiência nem a forma como o pai lida com uma criança especial.

Esses seriam os livros que, na bela metáfora de Sophie Rabau ${ }^{5}$, o escritor catarinense leu com uma "caneta pena na mão" (tradução da autora), estabelecendo uma rede intertextual capaz de integrar épocas e culturas distintas. Mais do que simplesmente mapeá-la, porém, é necessário se debruçar sobre os alcances desse diálogo, a fim de que o cotejo estabelecido repercuta nas leituras das obras em questão.

Assim, um dos principais propósitos deste artigo é mostrar como o romance italiano e o brasileiro lidam com a ideia de normalidade, desencadeando uma reflexão sobre como a presença velada ou explícita de padrões não apenas molda a relação com o outro, mas também acarreta, nos protagonistas, um novo olhar sobre si.

Vale acompanhar algumas etapas da construção histórica do conceito de normalidade para empreender a análise proposta. Segundo Lennard Davis ${ }^{6}$ a ideia de norma e normalidade são bastante recentes - os termos, inclusive, somente são utilizados nessa acepção em língua inglesa em meados do século XIX. No século XVII, ao invés de as comparações serem pautadas pela ideia de norma, estava em jogo a noção de ideal, associada ao divino, de que o ser humano podia em alguma medida se aproximar, mas sem nunca atingir. Para Davis, essa hegemonia da norma, muito mais recente do que parece ser, ganha força após a industrialização, com o advento da estatística. A concepção de normalidade é proposta, pela primeira vez, pelo estatístico Adolphe Quetelet, que lança o conceito de "homem médio", tanto em termos físicos quanto morais. Muito rapidamente, essa proposta extrapola a dimensão individual e atinge a classe social, com a criação, por exemplo, do conceito de classe média.

Com a propagação da ideia de norma, o modelo atrelado ao conceito de ideal é substituído por outro, marcado pela noção de extremo e desvio, o que repercute diretamente no modo de lidar com os portadores de deficiência, vistos, a partir de então, como desvios do padrão. Entretanto, uma vez que muitos estatísticos eram eugenistas e almejavam a eliminação gradual

1 A alusão às obras que influenciaram a escrita do livro é recorrente nas entrevistas do escritor catarinense. É o que ocorre, por exemplo, em TEZZA, Cristovão. A eternidade e um livro [entrevista concedida a Irineo Netto]. Gazeta do Povo, Curitiba, 6 ago. 2007. Disponível em:

$<$ http://www.cristovaotezza.com.br/critica/ficcao/f filhoeterno/p 03 gazetadopovo05ago07.htm $>$. Acesso em: 26 mar. 2020.

2 OE, Kensaburo. Uma questão pessoal, 2003.

3 PONTIGGIA, Giuseppe. Nascer duas vezes, 2002

4 COETZEE, John Maxwell. Juventude, 2013.

5 RABAU, Sophie. L'intertextualité, 2002, p.170.

6 DAVIS, Lennard. "Constructing Normalcy: the Bell Curve, the Novel, and the Invention of the Disabled Body in the Nineteenth Century", 1995, p. 23-72. 
de elementos destoantes em nome de uma suposta evolução da espécie, desponta o desejo de converter para a norma, aproximar-se dela, o que é explicitado por um comentário de Foucault: “a norma traz consigo ao mesmo tempo um princípio de qualificação e um princípio de correção. A norma não tem por função excluir, rejeitar. Ao contrário, ela esteve sempre ligada a uma técnica positiva de intervenção e de transformação, a uma espécie de poder normativo"”.

Esse poder normativo, nas obras estudadas, reflete-se na forma como os pais realizam, nos primeiros anos após o nascimento das crianças, uma gama de esforços para negar ou ao menos minimizar a anormalidade dos filhos. Em Nascer duas vezes, narrado em primeira pessoa, aquilo que o escritor brasileiro chamará de "angústia da normalidade" exemplo, no cuidado do narrador e de sua esposa para que o filho vá bastante descansado às consultas:

Tentamos fazer com que Paolo não se canse antes da consulta, recomendamos a ele o que falta a nós: calma. Ficamos angustiados toda vez que erra, e ele erra mais do que de costume, quase para dar uma justificação objetiva a nosso pânico. Receio que nós é que sejamos um casal de monstros, atormentados pelo medo, concordes apenas na absurda esperança de superálo. Deveríamos antes apresentá-lo nas piores condições, para evitar um diagnóstico conciliador e conseguir um mais críve?

O medo da forma como Paolo será visto pelos profissionais da saúde domina o casal que, mesmo sem sucesso, tenta induzir o filho a errar menos, pois a perspectiva de um desvio irreversível dos padrões é avassaladora. Com o passar do tempo, a sombra da normalidade que leva o narrador a pedir a Deus para curar o filho, primeiro completa e depois parcialmente - não se dissipa. Diante da incapacidade da criança de resolver algumas contas, o pai, a mãe e a avó amenizam a situação, alegando terem também dificuldades em matemática. O comentário do narrador, porém, explicita o quanto ele reconhece o próprio embuste: "Abaixo a cabeça. Não é preciso muito para transformar uma conversação numa farsa" ${ }^{\prime 10}$. A despeito dessa consciência, porém, o fantasma da anormalidade cria uma gama de ilusões e esperanças, da qual a família leva tempo para se livrar.

Já em $O$ filho eterno", a fase marcada por um "simulacro de normalidade"12 ganha mais força, pois a rejeição do pai ao filho que não corresponde à sua imagem e semelhança está diretamente associada à deficiência. Já ao nascer, os médicos diagnosticam a síndrome de Down, mas, apesar de todas as evidências, a esperança de o cariótipo não acusar o terceiro cromossomo se configura como uma última e improvável carta na manga. Mesmo após a

7 FOUCAULT, Michel. Os anormais, 2001, p.62.

8 TEZZA, Cristovão. O filho eterno, 2007, p.40.

9 PONTIGGIA, Giuseppe. Nascer duas vezes, 2002, p.88.

10 Ibidem, p.88.

11 TEZZA, Cristovão. O filho eterno, 2007.

12 Ibidem, p. 39. 
confirmação genética, porém, o pai lembra de ter lido em uma monografia sobre a existência de crianças que, portadoras da trissonomia do cromossomo 21, apresentam apenas os traços físicos da síndrome, sem nenhuma perda cognitiva. Mais uma vez, a esperança se frustra, mas a família não desiste de aproximar Felipe de um padrão de normalidade. Por isso, o pai e a mãe o levam a uma clínica especializada no Rio de Janeiro, onde crianças com diferentes tipos de deficiência são submetidas a uma rotina exaustiva de exercícios, dentre os quais alguns se assemelham a uma sessão de tortura (como colocar nos pacientes máscaras que dificultam a respiração para que, na tentativa de recuperar o ar, o cérebro seja mais oxigenado). Ao tomar contato com esse programa de superestimulação, cujo objetivo seria deixar as crianças o mais possível "parecidas com seres humanos"13, o pai sente que lhe dão um mapa, um manual de instruções para lidar com Felipe, até então não visto como um filho, mas sim como um problema a ser resolvido. Ao voltar para casa, a família segue à risca as instruções da clínica, perseguindo a promessa de normalidade implícita naquele treinamento - a qual, com o passar do tempo, revela-se uma miragem:

Volta-lhe a sensação de fracasso - algum dia o seu filho vai falar, vai ler, vai escrever, vai se civilizar? Sente a realidade bruta: como sempre, é preciso não mentir. Não, o seu filho jamais será uma criança normal - nem chegará perto disso. Viveu uma febre durante dois anos, um breve delírio dos sentidos, um véu de ilusão ${ }^{14}$.

Com a queda desse "véu de ilusão" nas duas obras analisadas, coloca-se a questão: como lidar com a anormalidade irreversível da criança? Como o modo de encarar a realidade do filho repercute no olhar que o pai lança sobre os outros e sobre si? Cada um dos livros proporá respostas distintas a essas questões.

A mudança no conceito de normalidade na psicanálise contribui para melhor compreender a reviravolta presente nas obras analisadas. Maria Regina Prata ${ }^{15}$ elucida que, se até 1920 predominava no pensamento de Freud a concepção, difundida entre seus contemporâneos, da anormalidade como um problema por romper um equilíbrio homeostático que deveria ser restituído, a criação da ideia de pulsão de morte rompe com esse sistema. O desequilíbrio e a dificuldade de estabilidade por conta da luta entre duas forças - a pulsão de vida e a pulsão de morte - seria inerente ao ser humano, o que implica necessariamente repensar a ideia de anormal e de cura. Assim, a meta da psicanálise não seria "eliminar todas as peculiaridades humanas em favor de uma normalidade esquemática"16. Nesse novo prisma, as fronteiras ficam

13 Ibidem, p.85.

14 Ibidem, p.127.

15 PRATA, Maria Regina. "O normal e o patológico em Freud”. Physis, vol.9 n.1., jan./jun 1999.

16 Sigmund Freud, apud PRATA, Maria Regina. "O normal e o patológico em Freud”. Physis, vol. 9 n.1, jan./ jun. 1999 , p.77. 
mais tênues, tornando a separação entre normal e anormal, doentio e são - até então rígida bastante dinâmica e fugidia, o que se reflete tanto no livro de Tezza quanto no de Pontiggia.

Em Nascer duas vezes, o narrador tem consciência do quanto o olhar dos outros sobre o filho é atravessado por um jogo de espelhos e projeções:

\begin{abstract}
Se uma criança portadora de deficiência é inesperadamente colocada num grupo de crianças, todas no início a olharão com curiosidade ou espanto ou perturbação, conforme a inexorabilidade dos pontos de vista. As únicas a conservarem uma atenção concentrada, uma participação ambígua e um olho torpe serão as que nela buscam um espelho. Algumas, tão fascinadas quanto vencidas pelo medo de se reconhecerem nela, reagirão até com a fuga ou a agressividade ${ }^{17}$.
\end{abstract}

Sob esse viés, a pessoa deficiente incomoda, porque desencadeia no outro o medo de se deparar com seu próprio quinhão de desvio da norma, com suas próprias diferenças. Assim, ao se irritar com o fato de o filho mais velho rir com os tropeços e erros de Paolo, o narrador percebe que de certo modo o compreende e constata: "Relutamos em aceitar, agigantados nos outros, os defeitos que receamos ter" ${ }^{\prime 18}$.

Essas projeções atingem seu grau máximo na figura do avô materno de Paolo, um funcionário influente de uma editora, muito preocupado com a saúde, com o corpo e que não se conforma em envelhecer. Já no nascimento do neto, explicita seu medo de o bebê se tornar, segundo suas palavras, um "idiota" e, a despeito de todas as evidências, morre com a crença de que apenas a aparência e as características físicas diferenciavam Paolo dos demais. Detendo-se sobre a postura do sogro, o narrador comenta:

\footnotetext{
Paolo oferecia-lhe uma oportunidade extrema para se rever, mas era a última coisa que ele gostaria de fazer. Dominado por uma ideia hierárquica da natureza e da sociedade, tinha de opor-se à condição do neto, que propunha problemas insolúveis ao seu sentido da vida. O diferente nos faz sentir diferentes - contrariamente ao que se pensa - e é isso que não estamos dispostos a perdoar ${ }^{19}$.
}

A incapacidade do sogro de se rever, a partir das lentes de uma pessoa de sua família que sai dos padrões, remete à dificuldade de lidar com a diferença do outro, mas também com suas próprias peculiaridades. Assim, a resistência em mudar sua concepção limitada de mundo - que o fazia, quando jovem, espancar homossexuais para lhes dar uma lição - sugere que ele, ao exibir orgulhosamente sua normalidade, seja talvez o que mais tema qualquer desvio de padrão que tem ou possa vir a ter.

17 PONTIGGIA, Giuseppe. Nascer duas vezes, 2002, p.41.

18 Ibidem, p.59.

19 Ibidem, p.84. 
Nas últimas páginas de seu livro, Pontiggia propõe uma aproximação entre deficiência e velhice, a qual dá novas nuances a essa questão. Segundo o narrador, com o passar dos anos, a deficiência passa a ser "um ente querido, uma experiência familiar, encarna-se em modo visível nos outros, antes de se instalar em nós mesmos" ${ }^{20}$. Esse movimento, que suscita outro olhar sobre o tema, é trabalhado principalmente a partir dos lapsos de memória e problemas cognitivos que o avô de Paolo passa a apresentar. Quando completa 88 anos, ele, que até então ridicularizava a esposa por confundir os personagens históricos ao fazer palavras cruzadas, torna-se incapaz de encontrar o nome de coisas bastante prosaicas. A família opta por poupá-lo da consciência de seu novo estado - inclusive por recomendação do médico, que aconselha a contradizê-lo o mínimo possível.

Em um jantar, a situação ganha traços caricaturais. Entre os convivas, estava Marco que, após realizar uma traqueotomia para extirpar um tumor, precisava apertar uma válvula sob a camisa para conseguir falar. O narrador, por sua vez, acometido por uma espécie de afonia, dosava suas intervenções, pois, segundo um especialista, devido ao excesso do uso da voz em sua profissão, ele não podia mais falar à vontade como uma pessoa normal. Embora o sogro exibisse lapsos de todas as ordens, procurando freneticamente o nome de coisas banais, quando ele pedia qualquer esclarecimento, "tudo parecia normal"21. Porém, quando o narrador disse algo e sua voz saiu rachada, tanto seu cunhado Marcos quanto seu sogro se pronunciaram prontamente e de forma ríspida, como se o acusassem por sua deficiência vocal. A cena, na qual a manutenção de uma ilusão de normalidade do avô de Paolo se assemelha a uma caricatura, deixa claro que não importa muito a natureza dos desvios de padrão - os quais todos têm ou vão ter - mas sim quem os apresenta. Nesse caso, o narrador, sempre desvalorizado pela família da esposa, configura-se como um espelho retorcido para o sogro e o cunhado, refletindo as anomalias de saúde que ambos têm em maior grau, mas não conseguem reconhecer em si mesmos.

Apesar de haver, no encontro aludido, uma aproximação projetiva entre o narrador e seu filho por conta da deficiência - inata ou desenvolvida com a idade -, esse não é um movimento predominante em Nascer duas Vez̧es. O filho eterno, por sua vez, é perpassado por equiparações entre o pai e Felipe - talvez porque, graças ao narcisismo paterno, essa foi a única forma encontrada por ele de aceitar um filho à primeira vista tão diferente de $\mathrm{si}^{22}$. No livro de Tezza, a representação da normalidade sofre algumas oscilações:

Não, nada mais será normal na sua vida até o fim dos tempos. Começa a viver pela primeira vez, na alma, a angústia da normalidade. Ele nunca foi

20 Ibidem, p.180.

21 Ibidem, p.198.

22 LORENZI, Camila Lousana Pavanelli de. "Uma aproximação da crítica literária à psicanálise na leitura de O filho eterno, de Cristóvão Tezza: relações entre leitor, narrador e personagem”. Jornal de psicanálise, vol. 45 n. 82,jun. 2012. 
exatamente um homem normal. Desde que o pai morreu, muitos anos antes, o seu padrão de normalidade se quebrou ${ }^{23}$.

Ao se sentir condenado a não ter mais uma vida convencional por conta da deficiência do filho, o escritor reconhece nunca ter sido um homem normal. A percepção desse desvio do padrão sugere o quanto até então desejava sentir-se um ser de exceção:

E quer manter intacto o orgulho, o sentimento da própria superioridade, que custou tanto a alimentar, que foi sempre a direção cega da sua vida - ou não teria feito nada, ou teria sido igual a todo mundo, carimbando formulário em algum balcão, puxando o saco de alguém, dependendo da própria gentiliza e da gentileza alheia, pedindo favor, sendo aquilo que todos os outros são, no seu olhar incompleto. Essa porcariada toda, esse lixo que ele vê em volta. Eu não quero isso. Eu nunca quis isso ${ }^{24}$.

Ainda tendo em vista a construção da normalidade, Lennard Davis ${ }^{25}$ mostra a reviravolta promovida por Galton, que fez ressalvas ao modelo da curva de Bell por lidar com os dois extremos da mesma forma. O estatístico opta por tirar o foco da ideia de média, substituindo-a pela de ranking-um modo de privilegiar os desviantes socialmente valorizados, como aqueles com habilidades fora do comum. Essa reformulação ecoa no trecho citado, em que fica claro o quanto o pai se vangloria por não ser uma pessoa dentro dos padrões, enaltecendo sua diferença como um sinal de superioridade. Quando nasce o filho portador de deficiência, porém, esse orgulho da anormalidade transforma-se em vergonha, em um golpe a sua imagem pessoal de que tem muita dificuldade para se restabelecer: “...seu filho quebrou-lhe a espinha, tão cuidadosamente empinada" ${ }^{26}$. De fato, o livro retrata em vários momentos esse pai envergonhado, incapaz de falar sobre o filho com os colegas e que, diante de perguntas a respeito da criança, responde sempre de forma evasiva. Com o processo de transformação do olhar que a relação com o filho suscita, o pai começa a perceber em si traços dessa anormalidade pouco lisonjeira:

Pensa na teimosia: o seu filho é teimoso. Faz parte da síndrome, ele sabe, a circularidade dos gestos e das intenções, que se repetem intensivamente como um disco riscado que não sai da sua curva - mas o pai também é teimoso, e mais obtuso ainda, porque sem a desculpa da síndrome ${ }^{27}$.

Instaura-se aos poucos na obra um leque de equiparações entre eles, evidente, por exemplo, no emprego da palavra "autista" para se referir a ambos e pelo reconhecimento,

23 TEZZA, Cristovão. O filho eterno, 2007, p.40.

24 Ibidem, p.52.

25 DAVIS, Lennard. "Constructing Normalcy: the Bell Curve, the Novel, and the Invention of the Disabled Body in the Nineteenth Century", 1995, p. 23-72.

26 TEZZA, Cristovão. O filho eterno, 2007, p.40.

27 Ibidem, p.129. 
por parte do escritor, da própria dificuldade de crescer e lidar com a realidade: "Eu também estou em treinamento, ele pensa, lembrando mais uma recusa da editora. A vida real começa a puxá-lo com violência para o chão, e ele ri imaginando-se no lugar do filho, coordenando braços e pernas para ficar em pé no mundo com um pouco mais de segurança" 28 . No âmago dessas aproximações, desponta a representação do escritor como alguém que tem dificuldade de caminhar sozinho, pagar as próprias contas e encontrar um lugar no mundo - em uma possível retomada irônica do "Albatroz", de Baudelaire, poema no qual, ao invés de a ênfase recair sobre as asas de gigante que impedem de andar, recai sobre os passos desengonçados de alguém inapto para viver na realidade.

Merecem atenção também os contrastes existentes no modo como os pais e os filhos lidam com a deficiência. Ao abordar a forma como as pessoas interpretam a forte relação de Paolo com a religião, o narrador de Nascer duas vezes comenta que os portadores de deficiência

\footnotetext{
Têm uma procuração coletiva para sofrer pelos outros. E sua carga agigantase, porque ali se oculta a carga universal. A realidade, porém, é ligeiramente diferente. Acostumados a viver com a desvantagem - e a suportá-la - os portadores de deficiência não têm dela a imagem insuportável de quem é sadio $^{29}$.
}

Diante da tendência geral de transformar as restrições do grupo em questão em uma metáfora de chagas universais, fica claro o quanto as projeções dos outros ganham muito mais espaço do que a própria percepção das pessoas detentoras dessas limitações - para quem, aliás, elas são naturalizadas e, portanto, mais leves. No livro de Pontiggia, uma viagem feita pela família às Ilhas Gregas é um marco para refletir sobre este ponto da discussão. Quando chegam à Grécia, os funcionários do aeroporto providenciam um elevador para o rapaz desembarcar. Seus pais, diante dessa situação imprevista, ficam bastante constrangidos e não deixam de frisar que o filho poderia descer do avião com as próprias pernas, do mesmo modo que embarcou na Itália. Essa não é, entretanto, a reação de Paolo:

\footnotetext{
Imagino, mais do que seu constrangimento (que é nosso), seu orgulho. Se exageram sua deficiência, para ele é melhor do que se o subestimam. Ao sair da cabina, apoiando-se numa aeromoça muito compenetrada em seu papel, sorri contra o sol, protegendo os olhos com a mão, e nos cumprimenta sem nos $\operatorname{ver}^{30}$.
}

Enquanto o narrador e sua esposa Franca não conseguem disfarçar seu mal-estar diante do elevador, que explicita o caráter de exceção do filho, este não esconde sua satisfação pelo tratamento especial dado a ele - dissonância de sentimentos também presente quando a família

28 Ibidem, p.130.

29 PONTIGGIA, Giuseppe. Nascer duas vezes, 2002, p. 162.

30 Ibidem, p. 166. 
é recebida de forma particularmente festiva no hotel. Em O filho eterno, essa preocupação com o olhar dos outros também se faz presente:

Sim, a criança não se concentra muito, diz a fonoaudióloga, e ele se afasta dali quase arrastando o filho, e no corredor como que sente o olhar agudo dos outros para o pai que leva aos trancos uma pequena vergonha nas mãos, incapaz de repetir duas ou três palavras num sentença simples. (E no entanto a criança abraça-o com uma entrega física quase absoluta, como quem se larga nas mães da natureza e fecha os olhos) ${ }^{31}$.

O contraste dessa cena merece destaque. De um lado, há a postura do pai que, envergonhado por ter um "filho idiota" 32 , sente-se julgado, provavelmente por projetar sua própria visão nos outros, e quer escapar do consultório o mais rapidamente possível. De outro, há o comportamento de Felipe, que se entrega ao abraçá-lo de forma intensa e, com olhos fechados, não se preocupa com o mundo e com os olhares ao redor. Esse abraço forte parece se configurar como um modo silencioso de comunicar-se: embora sem saber articular palavras, o filho consegue, com seu gesto, desarmar a pressa do pai, inserindo-o em seu próprio tempo. Com efeito, as duas obras são marcadas por momentos em que habilidades e perspectivas de comunicação caracterizam-se pela ausência de razão e de linguagem:

\footnotetext{
Um amigo, anos atrás, disse-lhe que, pela afetividade em estado puro, a criança atinge uma compreensão superior da vida e do mundo. A afetividade é sua compreensão - e, agora sim, a ideia bateu fundo na cabeça do pai. Há um toque de verdade nisso, ele pensou - o mundo dos afetos é o talento dessa criança ${ }^{33}$.
}

Ao finalmente entender a fala de um amigo, o professor reconhece um talento de Felipe, que, devido à sua capacidade de entrega, teria acesso a uma compreensão privilegiada do mundo. Essa é a primeira vez em que a percepção de uma diferença do filho não é vista como uma desvantagem, mas sim como uma peculiaridade identitária bastante positiva. É pela via do afeto que Felipe se distingue do pai, sem que essa discrepância seja associada a um problema. Em Nascer duas vezes, Paolo também é colocado como superior devido ao modo como lida com questões emocionais: "Ele sempre sente o que sinto somente nos estados de graça: simpatia pelo mundo. E o mundo o retribui" ${ }^{34}$.

Mais do que pensar em uma hierarquia entre formas distintas de apreender a realidade, vale destacar o quanto as habilidades atribuídas a Paolo e Felipe prescindem da linguagem formal, manifestando-se, muitas vezes, apenas por gestos e olhares, em silêncio. As duas personagens

31 TEZZA, Cristovão. O filho eterno, 2007, p. 145.

32 Ibidem, p. 145.

33 Ibidem, p. 186.

34 PONTIGGIA, Giuseppe. Nascer duas vezes, 2002, p.168. 
paternas, entretanto, extremamente imersas no universo das palavras, levam tempo para reconhecer essa perspectiva. No romance italiano, quando a professora do rapaz vai até a casa da família para conhecê-los, Franca comenta uma fala do filho ao interfone: “ 'Ele está atento apenas à linguagem, não the dê muita atenção', intervém com alegria. 'Há tantas coisas que não passam pela linguagem!"35. O narrador, porém, sorri diante dessa afirmação, descartando essa possibilidade, cujo teor de verdade - confessa em seguida - reconheceria duas décadas depois.

Em Filho Eterno, a incapacidade de Felipe de compreender metáforas e se alfabetizar completamente torna-se um muro que o separa do pai: "Ele jamais fará companhia ao meu mundo, o pai sabe, sentindo súbita a extensão do abismo, o mesmo de todo dia [...]”36. Porém, essa sensação de afastamento inevitável é em seguida nuançada por um gesto capaz de aproximálos: "e, no entanto, o menino continua largando-se no pescoço dele todas as manhãs, para o mesmo abraço sem pontas." ${ }^{37}$. Um comentário de David Lapoujade ${ }^{38}$ ajuda a entender essa forma de comunicação, potente e silenciosa, utilizada pelos dois rapazes:

Será que não há um fundo vital de emoções ou de afetos que permanece silencioso, simplesmente porque jamais lhe é concedido o direito de se exprimir? Não é cada experiência que reclama, de maneira surda, silenciosa, um direito à expressão? As emoções e os afetos nunca respondem às questões que o mundo nos coloca, elas respondem sempre, por assim dizer, à margem, porque procedem de outro foco ${ }^{39}$.

Nesse prisma, os afetos e as emoções, alheios às demandas pragmáticas do mundo social, requerem outros parâmetros de expressão, na maior parte das vezes ignorados, o que os reduz ao silêncio. Se, como propõe Lapoujade, a linguagem é um "vasto sistema de obrigações" pois quem fala tem obrigação de responder - o que, em diálogos, torna o silêncio uma recusa significativa - não é anódina a escolha de Paolo e Felipe por uma comunicação silenciosa. Essa forma de comunicar-se, entendida pela teórico como uma contralinguagem, talvez seja a única capaz de livrá-los do jogo social e das expectativas paternas, permitindo-lhes expressar com mais liberdade elementos identitários amiúde escamoteados.

Nas cenas finais dos dois livros, a discussão sobre a questão da alteridade atinge uma dimensão ainda maior. Em O filho eterno, pai e filho especulam sobre o resultado de uma partida de futebol - esporte apreciado pelos dois e responsável por ajudar a amadurecer em Felipe a percepção de tempo, além se ser importante em seu processo de alfabetização. O rapaz, entusiasmado com a perspectiva de vitória de seu time, ameaça os jogadores adversários:

\footnotetext{
35 Ibidem, p. 90.

36 TEZZA, Cristovão. O filho eterno, 2007, p. 221.

37 Ibidem, p.221.

38 LAPOUJADE, David. “O inaudível - uma política do silêncio”, Mutações - o Silêncio e A Prosa do Mundo, 2014.

39 Ibidem, p. 174-175.

40 Ibidem, p. 164.
} 
- Eles vão ver o que é bom para tosse!

É uma das primeiras metáforas da sua vida, copiada de seu pai, e o pai ri também. Mas, para que a imagem não reste arbitrária demais, o menino dá três tossidinhas marotas. Bandeira rubro-negra devidamente desfraldada na janela, guerreiros de brincadeira, vão enfim para a frente da televisão - o jogo começa mais uma vez. Nenhum dos dois tem a mínima ideia de como vai acabar, e isso é muito bom ${ }^{41}$.

Em um primeiro momento, o emprego da metáfora parece assinalar o ingresso de Felipe no universo do escritor, mas, ao tossir para que sua frase não soe arbitrária, ele lembra, através de sua incapacidade de lidar com formulações simbólicas, quem ele é. A impossibilidade de ser uma cópia narcísica do pai não os impede, porém, de se aproximarem: os dois, a despeito de suas diferenças individuais, sentam lado a lado, unidos pela total ausência de domínio sobre o que irá acontecer no imprevisível jogo de futebol, diante do qual são igualmente impotentes, como todos são, de forma mais ampla, diante do futuro. Eles, independentemente de suas habilidades intelectuais ou emocionais, tornam-se espectadores, imersos completamente no presente - e aqui a superioridade paterna na forma de lidar com o tempo não tem nenhuma serventia.

No desfecho do livro, a aproximação entre os dois não se dá por projeções, mas sim através de um papel desempenhado por ambos, que se transformam em "guerreiros de brincadeira" ${ }^{42}$. Esse mesmo movimento, embora de forma mais proeminente, marca o final de Nascer duas vezes.

Antes de abordá-lo, porém, é preciso mencionar um ponto importante do romance atrelado à questão da alteridade. Certo dia, Bertoia, um aposentado de saúde frágil, pergunta ao narrador, em tom acusatório, se ele já tentou se colocar no lugar do filho. Eis como é descrita a tentativa fracassada dessa empreitada:

Tento pensar "Eu sou Paolo", mas tenho uma sensação de terror e de vertigem, eu não tenho nem seu passado nem seu futuro, não posso imaginar o que ele imagina, nem compartilhar nada do que ele vive. Nunca podemos, como se diz numa expressão temerária e horrorosa, entrar na cabeça do outro ${ }^{43}$.

Bertoia atribui a incapacidade paterna ao egoísmo, quando na verdade ela remete à consciência dos limites da apreensão do Outro. Logo após seu interlocutor afirmar categoricamente ter entrado na cabeça de Paolo, o narrador comenta: "O olhar é alucinado, não sei se a doença ou os remédios o tornam febril” ${ }^{\prime 4}$. Ou seja, ao seu ver, cruzar as fronteiras intransponíveis da

41 TEZZA, Cristovão. O filho eterno, p. 222.

42 Ibidem, p. 222.

43 PONTIGGIA, Giuseppe. Nascer duas vezes, 2002, p.175.

44 Ibidem, p.1 75 
individualidade só é possível em um estado de delírio, de franca alucinação. Se a pretensão de se colocar no lugar do filho está fora de cogitação, o desfecho do livro revela uma nova forma de vê-lo, bastante distinta das já analisadas até então.

No capítulo final, intitulado "A distância", o narrador descreve o hábito do rapaz de se deslocar, na rua onde moram, apoiando-se nos muros das casas, bem como a reação dos outros diante dele e vice-versa. O pai, algumas vezes, fecha os olhos e tenta imaginar que o está vendo pela primeira vez. É com o relato de algo ocorrido em um desses exercícios que Pontiggia encerra seu romance: "Certa vez, enquanto olhava para ele como se fosse outro, e eu, outro, cumprimentou-me. Sorria e encostou-se no muro. Foi como se tivéssemos nos encontrado para sempre, por um instante" 45 .

Esse encontro, fugaz, mas intenso, somente ocorreu quando ambos fingiram, em um pacto tácito, não serem pai e filho. É durante esse jogo de máscaras, porém, que o narrador mais se aproxima de Paolo como sujeito, distanciando-se das projeções que moldavam seu olhar sobre ele.

Lévy-Strauss $^{46}$ ajuda a compreender o alcance dessa encenação. Ao refletir sobre o modo como um antropólogo deve se portar diante de uma sociedade por ele desconhecida, destaca que sua postura não deve ser nem de identificação nem de distanciamento, mas sim de desprendimento. Com a proposta do antropólogo francês no horizonte, Todorov observa: "é preciso admitir que o 'eu é um outro' antes de poder descobrir que o outro é um eu”" ${ }^{47}$. Com efeito, esse deslocamento identitário, no qual o narrador abandona seu papel de pai, foi fundamental para que ele conseguisse ver seu filho como sujeito. Nesse breve instante, ambos se cumprimentam, como duas pessoas que se cruzaram pelo caminho. Esse reconhecimento é o máximo que se pode pretender com lucidez, descartando a possibilidade disparatada de sentir ou pensar fingindo ser quem não se é.

De fato, tanto no romance de Tezza quanto no de Pontiggia, a aproximação mais efetiva entre pais e filhos, na qual as projeções narcísicas e as comparações caem por terra, ocorre quando, de forma lúdica, finge-se ser um Outro. Não parece descabido entender esse movimento como uma metáfora da ficção que, como pontua Ricoeur, promove uma suspensão tanto do mundo quando da identidade costumeira e, ao propiciar uma "metamorfose lúdica do ego" 48 , configura-se como uma das experiências mais intensas de alteridade. Assim, é partir de uma encenação no desfecho das duas obras que, a despeito de normas e comparações, o pai pode sentar, de fato, ao lado do filho ou cumprimentá-lo, reconhecendo nele o distinto traçado de seus contornos de sujeito.

45 Ibidem, p.201.

46 LÉVY-STRAUSS, Claude. Tristes tropiques, 1965, p. 344.

47TODOROV, Tzvetan. Nous et les autres:: la réflexion française sur la diversité humaine., 1989, p. 122. Tradução da autora.

48 RICOEUR, Paul. Do texto à aç̧ão: ensaios de hermenêutica II, 1989, p. 124. 
Para Maurice Domino, em qualquer tipo de retomada intertextual, o escritor apresenta "uma atitude reflexiva que já tem uma função crítica"49, Tezza, ao dialogar com Pontiggia, elucida e amplia a reflexão empreendida pelo romancista italiano sobre o peso dos padrões que, de forma mais ou menos velada, atuam sobre o sujeito. No jogo de ecos estabelecido com o autor de Nascer duas vezes, sugere também que uma experiência intensa de alteridade talvez seja possível apenas em momentos fortuitos, quando, como em uma brincadeira, a identidade habitual é abandonada e abrem-se outras possibilidades no modo de ser e estar no mundo.

\section{Referências}

COETZEE, John Maxwell. Juventude. São Paulo: Companhia das Letras, 2013.

DAVIS, Lennard. "Constructing Normalcy: the Bell Curve, the Novel, and the Invention of the Disabled Body in the Nineteenth Century". Londres, Nova York: Verso, 1995. p. 23-72.

DOMINO, Maurice.”La réécriture du texte littéraire Mythe et Réécriture". Paris: SEMEN, n.3, 1987.

FOUCAULT, Michel. Os anormais. São Paulo; Martins Fontes, 2001.

LAPOUJADE, David. "O inaudível - uma política do silêncio". In: NOVAES, Adauto (org). Mutacões - o Silêncio e A Prosa do Mundo. São Paulo: Edições Sesc, 2014.

LÉVY-STRAUSS, Claude. Tristes tropiques. Paris: Plon, 1965.

LORENZI, Camila Lousana Pavanelli de. "Uma aproximação da crítica literária à psicanálise na leitura de O filho eterno, de Cristóvão Tezza: relações entre leitor, narrador e personagem”. In: Jornal de psicanálise, São Paulo, vol. 45 n. 82, jun. 2012.

OE, Kensaburo. Uma questão pessoal. São Paulo: Companhia das Letras. 2003.

PONTIGGIA, Giuseppe. Nascer duas vezes. São Paulo: Companhia das Letras, 2002.

PRATA, Maria Regina. “O normal e o patológico em Freud”. Physis, vol. 9 n. 1. Rio de Janeiro, jan./ jun. 1999.

RABAU, Sophie. L'intertextualité. Paris: Flammarion, 2002.

RICOEUR, Paul. Do texto à aç̧ão: ensaios de hermenêutica II. Porto: Res Ed., 1989.

TEZZA, Cristovão. A eternidade e um livro [entrevista concedida a Irineo Netto]. In: Gazeta do Povo, Curitiba, 6 ago. 2007. Disponível em: <http://www.cristovaotezza.com.br/critica/ficcao/f filhoeterno/p 03 gazetadopovo05ago07.htm $>$. Acesso em: 26 mar. 2020.

TEZZA, Cristovão. O filho eterno. Rio de Janeiro: Record, 2007.

49 DOMINO, Maurice.’La réécriture du texte littéraire Mythe et Réécriture”. SEMEN, n.3, 1987, p. 45. Tradução da autora.

outra travessia 27 - Programa de Pós-Graduação em Literatura 
TODOROV, Tzvetan. Nous et les autres: la réflexion française sur la diversité humaine. Paris: Éditions du Seuil, 1989.

Submissão: $14 / 04 / 2020$

Aceite: $03 / 07 / 2020$

https://doi.org/10.5007/2176-8552.2019.e72968

Esta obra foi licenciada com uma Licença Creative Commons Atribuição-NãoComercial 4.0 Internacional. 